\section{Índice craneano del antiguo poblador peruano precolombino con deformación cefálica artificial}

\author{
Cranial index of ancient pre-columbian peruvian population with artifi- \\ cial cephalic deformation
}

\section{Resumen}

Objetivo: el estudio consiste en precisar la forma craneana determinada por el índice craneano relacionándolo con el agente causal, el área cultural de procedencia de los cráneos y las tendencias morfo craneales obtenidas visualmente. Metodología: se empleó 18 cráneos precolombinos comprendidos en la clasificación tipológica de Pedro Weiss, en los cuales se procedió a la medición de los anchos interparietales máximos y longitudes anteroposteriores, medidos de la glabela al opistocráneo; empleando la fórmula matemática que multiplica el eu-eu por 100, dividido por la longitud gl-op. Los índices craneanos y formas craneanas son relacionados con el agente causal, el área cultural de procedencia de los cráneos y las tendencias dolicocefálicas y braquicefálicas establecidas visualmente en anterior estudio, buscando equivalencias con formas craneanas consideradas en la clasificación de Martin y Broca. Resultados y conclusiones: 1. Los cráneos peruanos precolombinos del área cultural costeńo con deformación artificial por cuna presentan formas hiper braquicéfalos según Martin con índice craneano promedio de 97.0, concordante con la percepción visual de su forma craneana. 2. Los cráneos peruanos precolombinos del área cultural andino con deformación cefálica artificial por llautu presentan formas dolicocéfalos según Martin con índice craneano promedio de 73.1, concordante con la percepción visual de su forma craneana. 3. Las formas craneanas determinadas por índice craneano son concordantes con las formas craneanas obtenidas visualmente por norma superior. Las discrepancias observadas podría deberse a la aplicación de artefactos semirrígidos que comprimían el opistocraneo y que permitía posiblemente a la expansión longitudinal compensatoria del cráneo a expensas del lambda.

Palabras Clave: Índice craneano; deformación craneal artificial; Perú precolombino; dolicocéfalos; braquicéfalos.

\section{Abstract}

Objective: The study is to point out the cranial shape determined by the cranial index in relation with the causal agent, the cultural area of skulls origin and cranial morphological trends visually obtained. Methodology: it was used, 18 pre-columbian skulls included in the typological classification of Peter Weiss, in which we proceeded to measure the width and anteroposterior interparietal maximum length, measured from the glabella to opistocráneo; using the mathematical formula that multiplies the eu-eu by 100 , divided by the length gl-op. Cranial indexes and cranial shapes are related to the causative agent, the cultural area of origin of the skulls and dolichocephalic and brachycephalic visual trends established in a previous study, seeking equivalence with cranial forms considered in the classification of Martin and Broca. Results and conclusions: 1 . The pre-columbian peruvian skulls from the coastal cultural area with artificial deformation by "cuna" presented brachycephalic forms according to Martin with a cranial index average of 97.0, consistent with the visual perception of the cranial shape. 2 . The pre-columbian peruvian andean cultural area skulls with artificial cephalic deformation "llautu" have dolichocephalous forms according to Martin averaging 73.1 cranial index consistent with the visual perception of the cranial shape. 3 . The cranial forms determined by cranial index are consistent with cranial forms visually obtained by a higher standard. The discrepancies observed may be due to applying the semi rigids artifacts that compressed opistocraneo and possibly allowed compensatory longitudinal expansion of the skull at the expense of lambda.

Keywords: Cranial index; artificial cranial deformation; pre-columbian Perú; dolichocephalic; brachycephalic.

\section{Introducción}

Los aborígenes que poblaron América descendieron de los antiguos pueblos mongoloides que cruzaron el estrecho de Bering hace 40,000 años; en cuya caracterización de sus formas craneanas el índice craneal ha desempeñado un papel estelar ${ }^{1}$. Broca (citado por Isabel Marti) ${ }^{1}$ en el siglo pasado define cinco grupos según el valor de sus índices: Dolicocráneos: 75 a menos, subdolicocráneos: 73,01 a 75,77; mesocráneos: 75,78 a 78,01; subbraquicráneos: 78,01 a 81,33; braquicráneos: 81,33 a más milimetros.
Luis Gálvez-Calla', Luis Maita-Veliz², Pedro Ballona-Chambergo? Arnaldo Munive-Degregori ${ }^{3}$ Victoria Ramos-Arteaga ${ }^{4}$,
1. Departamento de Ciencias Básicas.

2. Departamento Médico Quirúrgico.

3. Departamento de Estomatología Rehabilitadora

4. Escuela de Pregrado.

1-4 Facultad de Odontología de la Universidad Nacional Mayor de San Marcos, Perú.

Correspondencia:

Dr. Luis Gálvez-Calla

Facultad de Odontología de la Universidad

Nacional Mayor de San Marcos.

Av. Germán Amezaga 375 Lima 1, Perú

Correo electrónico: lugalca2005@gmail.com

Coautores

Maita: luismv@yahoo.com

Ballona: pedroballona@yahoo.es

Angeles: angeles20ramos@gmail.com

Munive: arnaldomunive@hotmail.com

Los factores geográficos afectan significativamente la forma de la cabeza y el índice cefálico, del mismo modo son afectados por la edad, el género, la raza y los grupos étnicos ${ }^{2}$.

En la medida que las poblaciones se alejan del ecuador y se acercan a los polos, 
aumenta el índice cefálico. Lo cual se debería a una respuesta adaptativa relacionada con la termorregulación ${ }^{3}$.

Se ha demostrado que la forma de la cabeza está relacionada significativamente a las zonas de estrés climático, ocurriendo tendencia hacia la braquicefalización a lo largo del Pleistoceno ${ }^{3,4}$

El índice craneal parece disminuir en climas entre templado/Glacial y aumenta en poblaciones no expuestas a las heladas de invierno; es decir experimentan un ligero aumento del índice craneal en ecotipos tropicales ${ }^{3,4}$

La altitud tiene un valor significativo sobre el índice craneano, siendo el efecto mayor que la antigüedad de los cráneos y la temperatura máxima y mínima anual ${ }^{1}$.

Ciertas evidencias hacen suponer que existe relación entre el índice craneal y la talla del individuo. Pittard señala que en un grupo dolicocefálico el individuo más alto tiene un índice cefálico menor; de igual modo el individuo más alto de un grupo braquicefálico ${ }^{5}$

En una muestra de 600 aymaras, los hombres alcanzaron valores de 77,0 de índice craneal (mesocéfalo) y las mujeres de 71,0 (dolicocéfalos) ${ }^{6}$.

Se afirma que en la población amerindia predomina la braquicefalia ${ }^{6}$.

Según Hartweg ${ }^{7}$ los Cabezas largas (Perú) de 5,000 años de antigüedad con índice craneal promedio de 75,0 (65,0$84,9)$ habitaban a $30 \mathrm{~m}$ de altura s.n.m.

En San Damián (Perú) ${ }^{8}$ a 3,000 m. de altura s.n.m., cráneos de 500 años de antigüedad, presentaron un índice craneal promedio de 80,7 (73,0-88,3).

En Chancay $(\text { Perú })^{8}$ a $30 \mathrm{~m}$. de altura s.n.m., cráneos de 500 años de antigüedad, presentaron índice craneal promedio de 79,5 $(72,0-87,0)$

En el Valle de Chicama, Moche y Virú (Perú) $)^{9}$ a 30 m. de altura s.n.m., se evaluaron cráneos de 500 ańos de antigüedad, con índice craneal promedio de 79,5 (68,2-90,7).

En Paucarcocha (Perú) ${ }^{10}$ a 3,000 m. de altura s.n.m. se estudiaron cráneos de 500 años de antigüedad con índice craneal promedio de 76,3 (69,7-82,9).

Es importantes el conocimiento detallado de las características biométricas del cráneo para el estudio y comparación craneal de poblaciones con diferentes orígenes raciales, para la evaluación del crecimiento y desarrollo de un individuo y para el diagnóstico de cualquier anomalía de tamaño y forma del cráneo.

El índice cefálico es un parámetro importante para evaluar las diferencias raciales y sexuales

En una población adulta de Sri Lanka los fenotipos cefálicos predominantes fueron braquicéfalos, hipsicefálicos $\mathrm{y}$ acrocéfalos. Entre los hombres predominaron los dolicocéfalos y entre mujeres los braquicéfalos. Los resultados de este estudio ponen de relieve la diversidad racial y las diferencias en la morfometría craneal e índice cefálico entre hombres y mujeres ${ }^{11}$.

A pesar de su importancia, poco se conoce sobre la morfometría craneal de las poblaciones precolombinas ${ }^{2}$

En el antiguo Perú, la forma de la bóveda craneana determinada visualmente en norma superior, se clasifica en dos grandes grupos: braquicéfalos (predominio de la anchura) y dolicocéfalos (predominio de la longitud) ${ }^{12}$; los primeros asociados a culturas costeñas vinculados a prácticas de deformación craneana por cuna; y los segundos asociados a culturas andinas vinculados a prácticas de deformación craneana por llautu. ${ }^{13}$

Sin embargo, el elevado índice cefálico encontrado en los cráneos aimaraes con el diámetro transverso de enorme proporción, debido a las visibles deformaciones de los huesos frontal y parietal asociadas a sus costumbres de achatar la cabeza de los niños con tablillas colocadas en la frente y región posterior de la cabeza. Estas deformaciones, que se hacían obedeciendo ritos religiosos, tienen que forzosamente alterar los diámetros del cráneo, constituyendo así medidas que no pueden tomarse en cuenta como características propias de una raza ${ }^{14}$. Es probable que en los pueblos aimaraes estas prácticas se deban a la influencia intercultural producto de la migración poblacional sumamente dinámica en la época.

De acuerdo a la clasificación de Broca (citado por Isabel Marti) ${ }^{1}$ el índice cefálico de los aimaraes han sido clasificados entre braquicéfalos y superbraquicéfalos, cuyas medidas craneométricas guardan relación entre las razas aimaras, Tolstecas y Natches del Norte ${ }^{14}$.

La Antropología moderna distingue a las razas especialmente de acuerdo a los índices craneanos. Inicialmente hubo dos razas primigenias: dolicocéfalas y braquicéfalas. De estas se han formado las variantes que hoy conocemos. No se consideran dentro las primigenias a la raza negra. Un claro ejemplo constituye la población andina, la más antigua del continente americano. Para esta clasificación solo se tomó en cuenta la cabeza que es la que menos sufre transformación excepto por la mestización, la deformación artificial y accidental ${ }^{15}$.

Las razas actuales se hallan mestizadas desde hace miles de años plenamente reconocidos por eminentes antropólogos; sin embargo quedan algunos grupos representativos de "razas puras" los Puquinas, los Uros y los Khollas ${ }^{15}$

Se consideran dos principales "razas andinas"15:

1. Los que están compuestos por individuos dolicocéfalos (cabeza alargada hacia el occipital), braquiprosopos (cara ancha), platirrhinos (nariz ancha), leptoestafilinos (paladar angosto), fenozigomáticos (juanetes sobresalientes), mesoconchos (ojo mongoloide o de forma almendrada en órbita baja), prognatos (mandíbula superior muy avanzada vista de perfil), etc.

2. Los que presentan características: braquicefalia (cabeza alta, achatada atrás), leptoprosopia (cara alargada), leptorrhinia (nariz fina y alargada), braquiestafílinia (paladar ancho), ortognato (mandíbula poco sobresaliente con dentadura aproximadamente vertical), hipsiconcho (ojo de forma foliolar o europeo, como también se llama al ojo en órbita alta).

El método más objetivo para determinar la forma de la bóveda craneal es utilizando el índice craneano en cráneos secos, llamado índice cefálico cuando se determina la forma craneal in vivo. Para lo cual se emplea la fórmula matemática que consiste en multiplicar el ancho interparietal máximo (eu-eu) por 100, dividiendo el producto por la longitud anteroposterior máxima del cráneo medida entre la glabela (gl) y el opistocráneo $(\mathrm{op})^{16}$

Este índice craneano permite clasificar la forma de la bóveda craneal visto por norma superior en: Hiperbraquicéfalos igual o más de 85,0; Braquicéfalos de 80,0 a 84,9; Mesocéfalos de 75,0 a 79,9; Dolicocéfalos de 70,0 a 74,9 e Hiperdolicocéfalos igual o menos de 69,9 que corresponde a la clasificación de Martin (citado por Morel, 1964) ${ }^{17}$

Se han realizado estudios en ese sentido en "Grupos Étnicos Precolombinos del Norte de Chile con Deformación Craneal Artificial" cuyos promedios de índice craneano en cráneos con deformación tabular (braquicéfalos) fue de 
92,63, SD 9,72 en Atacameños. Los cráneos aymaras con deformación circular o anular (dolicocéfalos), presentaron un promedio de índice craneano de 76,0, SD 6,66; habiendo diferencia significativa entre ellos ${ }^{18}$.

No obstante la influencia etnocultural de los Tiwanaku hacia el norte de Chile $^{18}$, cada provincia incaica tenía su propia forma de deformación cefálica ${ }^{13}$; este estudio se realizó con el fin de precisar la forma craneana determinada por el índice craneal del antiguo poblador peruano precolombino con deformación cefálica artificial según tipología de Weiss, relacionándolos con el área cultural de procedencia de los cráneos, el agente causal y las tendencias a formas craneanas (dolicocéfalas y braquicéfalas) determinadas visualmente en anterior estudio, estableciendo además equivalencias con los índices cefálicos y formas craneanas señaladas según la clasificación de Martin (citado por Morel) ${ }^{17}$ y Broca (citado por Marti) $^{1}$.

\section{Materiales y método}

Nuestro estudio se limitó a los grupos poblacionales precolombinos comprendidos dentro de la clasificación tipológica de Pedro Weiss

Se emplearon 18 cráneos precolombinos comprendidos dentro de la clasificación tipológica de Weiss, preservados como patrimonio cultural en la curaduría de restos humanos del $\mathrm{Mu}$ seo Nacional de Arqueología, Antropología e Historia del Perú.

Los citados cráneos no recibieron ningún tipo de intervención por ser de patrimonio cultural, estando sólo autorizado el análisis y la observación de los cráneos, razón por lo cual fueron íntegramente fotografiados en todas sus normas anatómicas. También se midió la longitud anteroposterior máxima de los cráneos y su anchura máxima craneal con la finalidad de determinar el índice craneano respectivo aplicando la fórmula matemática que multiplica el ancho interparietal máximo por 100 , dividido con la longitud anteroposterior máxima del cráneo medido entre la glabela y el opistocráneo.

Establecido los índices craneanos se valoraron y se buscaron las equivalencias con los índices cefálicos y formas craneanas señaladas según la clasificación de Martin (citado por Morel) ${ }^{17}$
Hiperbraquicéfalos igual o más de 85,0;

Braquicéfalos entre 80,0 y 84,9;

Mesocéfalos entre 75,0 y 79,9;

Dolicocéfalos entre 70,0 y 74,9 e

Hiperdolicocéfalos igual o menos de 69,9

Además se relacionaron con el área cultural de procedencia de los cráneos, el agente causal y las tendencias a formas craneanas (dolicocéfalas y braquicéfalas) determinadas visualmente en estudio anterior ${ }^{12}$.

\section{Resultados}

\section{a. Recopilación de datos}

Luego de haberse mensurado las dimensiones anteroposterior e interparietal máximos de los cráneos con deformación cefálica se establecieron los índices craneanos que se detallan en la Tabla 1.

\section{b. Procesamiento de datos}

Los índices craneanos obtenidos han sido vinculados en relación lineal con los índices y formas establecidos por Martin (Morel) y Broca (Marti); el área cultural de procedencia de los cráneos; el agente causal (aparato deformador) y las tendencias morfológicas obtenidas visualmente en norma superior. Cuyos resultados se encuentran detallados por separado en las tablas 2, 3, 4, y resumidos en la Tabla 5.

Los cráneos con deformación cefálica Fronto Occipital (Weiss) presentan un índice craneano promedio de 95.4; otro cráneo con deformación Inca Costeño (fig. 1) presenta 98.6 de índice craneano. Ambos cráneos, deformados por cuna, presentan forma craneana hiperbraquicéfala según la clasificación de Martin perteneciente al área cultural costeño.

Los cráneos con deformación cefálica Aimara (fig.2) presentan un índice craneano promedio de 74.75 ; los cráneos con deformación Opa presentan un índice craneano promedio de 71.45. Además los cráneos Aimara y Opa, deformados por llautu, presentan forma craneana dolicocéfala según la clasificación de Martin, congruente con la percepción visual y son pertenecientes al área cultural andino.

Los cráneos con deformación cefálica tipo Cavernas (fig.3), deformados por llautu, alcazaron un elevado índice craneano de 95.2, es decir de forma craneana hiperbraquicéfala según la clasificación de Martin concordante con la percepción visual, son pertenecientes al área cultural andino. Esta situación hace suponer que las culturas andinas lograban también deformaciones tabulares braquicéfalas utilizando el llautu.

Los cráneos con deformación cefálica tipo Huaura (fig.4), deformados por llautu y placas semirrígidas presentan un índice craneano promedio de 98.75, de forma craneana hiperbraquicéfala según la clasificación de Martin, son pertenecientes al área cultural andino. No hubo concordancia con la percepción visual dolicocéfala probablemente debido a la aplicación de placas semirrígidas en las regiones frontal y occipital (opistocraneo) permitiendo la expansión longitudinal compensatoria del lambda y zonas adyacentes.

Los cráneos con deformación cefálica tipo Cabeza Larga (fig.5) presentan índice craneal promedio de 87.7, de forma craneal hiperbraquicéfalo según Martin, concordante con la percepción visual y perteneciente al área cultural andino.

Los cráneos con deformación Necrópolis (fig.6) alcanzaron un índice craneal promedio de 93.7 de forma craneal hiperbraquicéfalo según Martin concordante con la percepción visual, perteneciente al área cultural andino.

Los cráneos con deformación cefálica tipo Natchez (fig.7) deformados por llautu más rosca algodón paracas presentan un índice craneano promedio de 86.05 de forma craneal hiperbraquicéfalo según Martin concordante con la percepción visual, sin embargo un cráneo Natchez de forma dolicocéfalo visto desde su norma superior presento forma braquicéfalo obtenido por índice craneano (82.9).

Un cráneo con deformación tipo Nazca (fig.8), deformado por llautu más rosca algodón paracas más almohadilla, presenta índice craneal de 79.7 mesocéfalo según la clasificación de Martin fue incongruente con la percepción visual dolicocéfalo, probablemente por la aplicación de placa semirrígida sobre el opistocraneo cusando posiblemente la expansión longitudinal a expensas del lambda. 


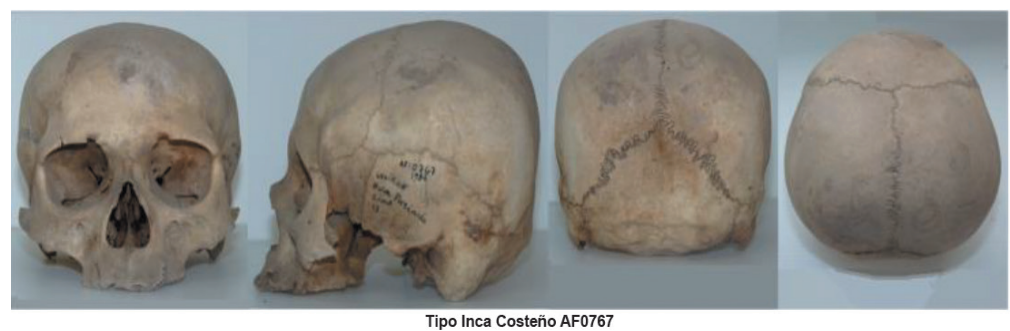

Fig. 1: Cráneo hiperbraquicéfalo (i.c.98.6) del área cultural costeño deformado por cuna

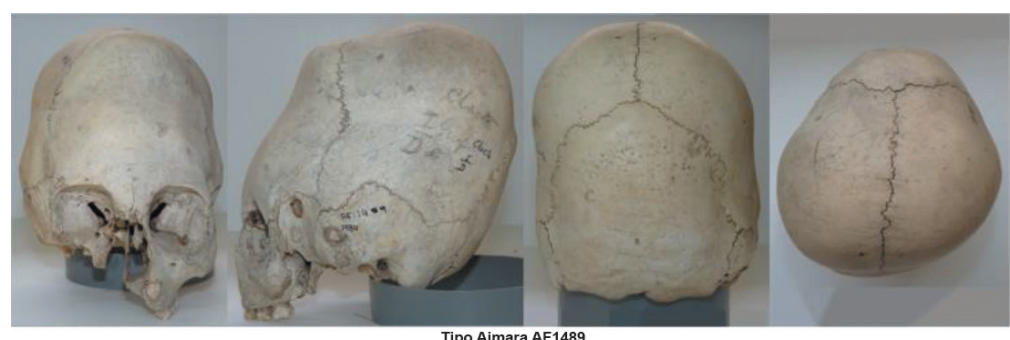

Fig. 2: Cráneo dolicocéfalo (i.c. 77.0) del área cultural andino deformado por llautu

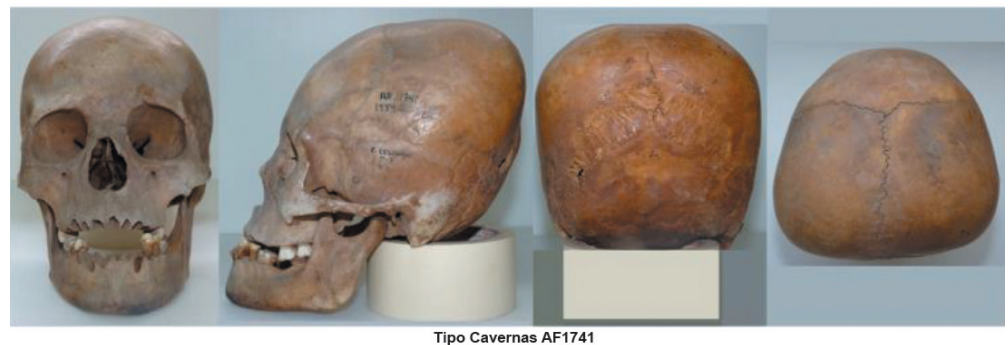

Fig. 3: Cráneo hiperbraquicéfalo (i.c. 95.2) del área cultural andino deformados por llautu

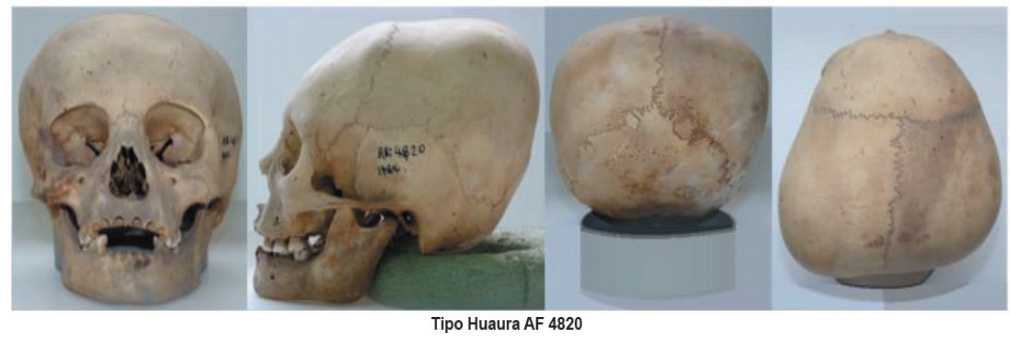

Fig. 4: Cráneo hiperbraquicéfalo (i.c. 104.4) del área cultural andino deformado por llautu

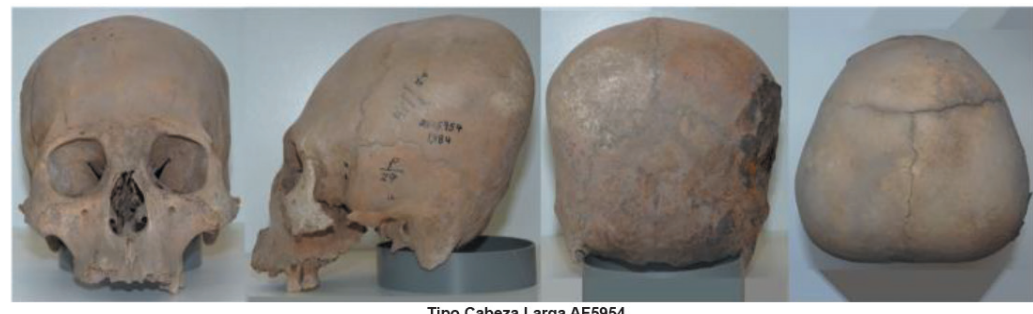

Tipo Cabeza Larga AF5954

Fig. 5: Cráneo hiperbraquicéfalo (i.c. 94.2) del área cultural andino deformado por llautu

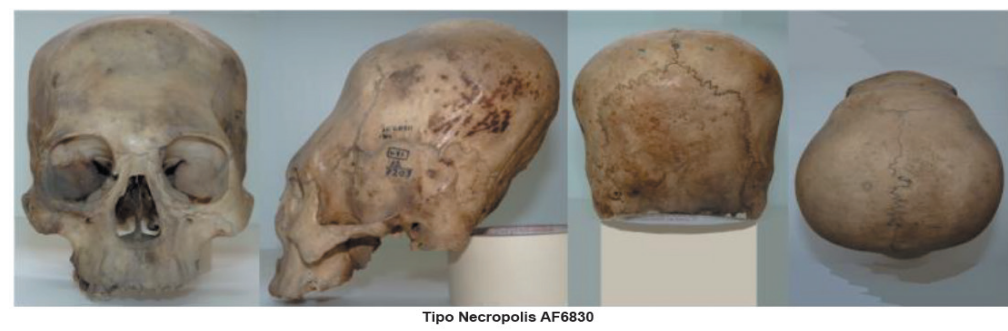

Fig. 6: Cráneo hiperbraquicéfalo (i,c. 94.5) del área cultural andino deformado por llautu 


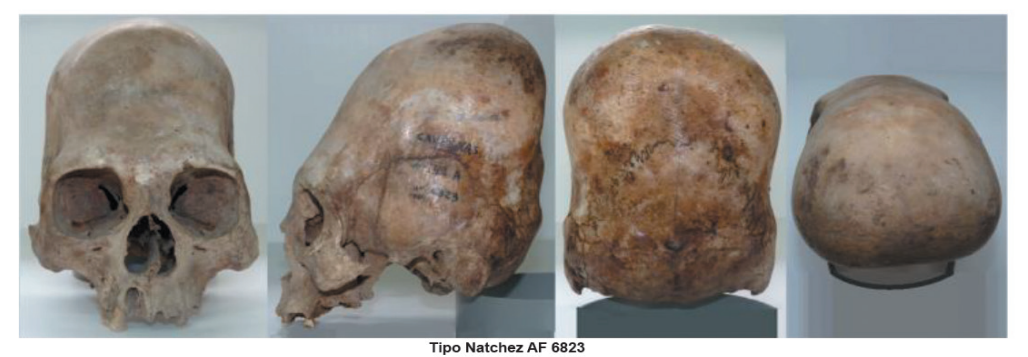

Fig. 7: Cráneo hiperbraquicéfalo (i.c. 82.9) del área cultural andino deformado por llautu

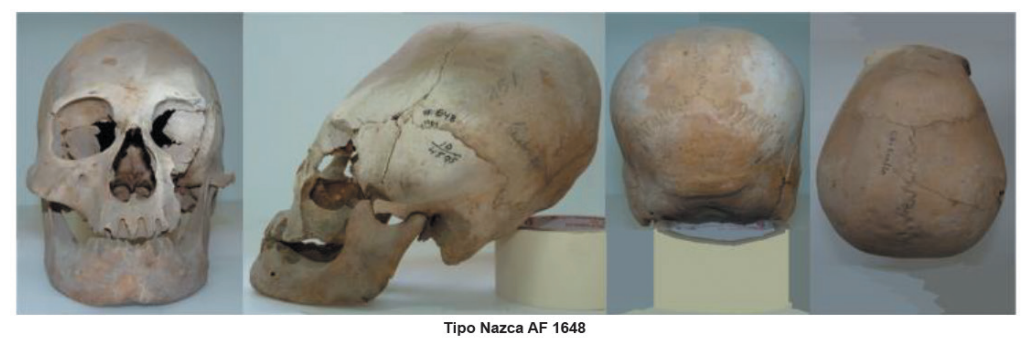

Fig. 8: Cráneo mesocéfalo (i.c. 79.7) del área cultural andino deformado por llautu

Tabla 1: Longitudes y anchos máximos de cráneos con deformación cefálica intencional según tipología de Weiss e índices craneanos respectivos

\begin{tabular}{clllll}
\hline $\begin{array}{c}\mathbf{N}^{\circ} \\
\text { Crá } \\
\text { Neos }\end{array}$ & $\begin{array}{l}\text { Cráneos } \\
\text { deformados } \\
\text { precolombinos } \\
\text { Tipología } \\
\text { de Weiss }\end{array}$ & $\begin{array}{l}\text { Códigos } \\
\text { MNAAHP }\end{array}$ & $\begin{array}{l}\text { Longitud } \\
\text { antero } \\
\text { posterior } \\
\text { máximo } \\
\text { Gl-Op }\end{array}$ & $\begin{array}{l}\text { Ancho } \\
\text { interparietal } \\
\text { máximo } \\
\text { Eu-Eu }\end{array}$ & $\begin{array}{l}\text { Índice } \\
\text { craneano }\end{array}$ \\
\hline 1 & Fronto occipital & AF 4885 & 16.7 & 15.5 & $\mathbf{9 2 . 8}$ \\
1 & Fronto occipital & AF 6025 & 15.2 & 14.9 & $\mathbf{9 8 . 0}$ \\
1 & Inca Costeño & AF 0767 & 14.4 & 14.2 & $\mathbf{9 8 . 6}$ \\
1 & Aimara & AF 1489 & 15.2 & 11.7 & $\mathbf{7 7 . 0}$ \\
1 & Aimara & AF 10870 & 17.1 & 12.4 & $\mathbf{7 2 . 5}$ \\
1 & Opa & AF 1577* & 15.4 & 11.0 & $\mathbf{7 1 . 4}$ \\
1 & Opa & AF 1643 & 19.1 & 13.65 & $\mathbf{7 1 . 5}$ \\
1 & Cavernas & AF 1741 & 14.7 & 14.0 & $\mathbf{9 5 . 2}$ \\
1 & Cavernas & AF 1763 & 14.6 & 13.9 & $\mathbf{9 5 . 2}$ \\
1 & Huaura & AF 1699 & 17.4 & 16.2 & $\mathbf{9 3 . 1}$ \\
1 & Huaura & AF 4820 & 14.75 & 15.4 & $\mathbf{1 0 4 . 4}$ \\
1 & Cabeza Larga & AF 2613 & 17.8 & 14.45 & $\mathbf{8 1 . 2}$ \\
1 & Cabeza Larga & AF 5954 & 15.65 & 14.75 & $\mathbf{9 4 . 2}$ \\
1 & Necrópolis & AF 6797 & 15.45 & 14.35 & $\mathbf{9 2 . 9}$ \\
1 & Necrópolis & AF 6830 & 15.35 & 14.5 & $\mathbf{9 4 . 5}$ \\
1 & Natchez & AF Momia 108 & 14.8 & 13.2 & $\mathbf{8 9 . 2}$ \\
1 & Natchez & AF 6823 & 14.0 & 11.6 & $\mathbf{8 2 . 9}$ \\
1 & Nazca & AF 1648 & 17.2 & 13.7 & $\mathbf{7 9 . 7}$ \\
\hline
\end{tabular}

*AF 1577 no hay basion - cráneo de nińa

Tabla 2: Equivalencias de índices craneanos de cráneos con deformación cefálica según tipología de Weiss con los índices craneanos y formas craneanas de Martin y Broca

\begin{tabular}{cllllll}
\hline $\begin{array}{c}\mathbf{N}^{\circ} \text { de } \\
\text { cráneos } \\
(\mathbf{1 8 )}\end{array}$ & $\begin{array}{l}\text { Cráneos deformados } \\
\text { precolombinos Tipolo- } \\
\text { gía de Weiss }\end{array}$ & $\begin{array}{l}\text { Índice } \\
\text { craneano }\end{array}$ & $\begin{array}{l}\text { Índice cranea- } \\
\text { no según Martin }\end{array}$ & $\begin{array}{l}\text { Forma craneana } \\
\text { (métrica) } \\
\text { Según Martin }\end{array}$ & $\begin{array}{l}\text { Índice cranea- } \\
\text { no según Broca }\end{array}$ & $\begin{array}{c}\text { Forma craneana } \\
\text { (métrica) } \\
\text { según Broca }\end{array}$ \\
\hline 2 & Fronto occipital & $95.4 \mathrm{p}$ & $85,0->85,0$ & Hiperbraquicéfalo & $81.33->$ & Braquicraneo \\
1 & Inca Costeño & 98.6 & $85,0->85,0$ & Hiperbraquicéfalo & $81.33->$ & Braquicraneo \\
2 & Aimara & 77.0 & $75,0-79,9$ & Mesocéfalo & $75.78-78.01$ & Mesocraneo \\
& & 72.5 & $70,0-74,9$ & Dolicocéfalo & $<-75$ & Dolicocráneo \\
2 & Opa & $71.45 p$ & $70,0-74,9$ & Dolicocéfalo & $<-75$ & Dolicocráneo \\
2 & Cavernas & 95.2 & $85,0->85,0$ & Hiperbraquicéfalo & $81.33->$ & Braquicráneo \\
2 & Huaura & $98.75 p$ & $85,0->85,0$ & Hiperbraquicéfalo & $81.33->$ & Braquicráneo \\
2 & Cabeza Larga & 81.2 & $80,0-84,9$ & Braquicéfalo & $81.33->$ & Braquicráneo \\
& & 94.2 & $85,0->85,0$ & Hiperbraquicéfalo & $81.33->$ & Braquicraneo \\
2 & Necrópolis & $93.7 p$ & $85,0->85,0$ & Hiperbraquicéfalo & $81.33->$ & Braquicráneo \\
2 & Natchez & 89.2 & $85,0->85,0$ & Hiperbraquicéfalo & $81.33->$ & Braquicráneo \\
& & 82.9 & $80,0-84,9$ & Braquicéfalo & $81.33->$ & Braquicraneo \\
1 & Nazca & 79.7 & $75,0-79,9$ & Mesocéfalo & $78.01-81.33$ & Sub-braquicráneo \\
\hline
\end{tabular}


Tabla 3: Relación de índices craneanos de cráneos con deformación cefálica según tipología de Weiss con el área cultural de procedencia y el agente causal

\begin{tabular}{|c|c|c|c|c|c|}
\hline \multirow{2}{*}{$\begin{array}{c}\mathrm{N}^{\circ} \\
\text { Cráneos }\end{array}$} & \multirow{2}{*}{$\begin{array}{l}\text { Cráneos deformados } \\
\text { precolombinos } \\
\text { Tipológica de Weiss }\end{array}$} & \multirow[b]{2}{*}{$\begin{array}{l}\text { Índice } \\
\text { craneano }\end{array}$} & \multicolumn{2}{|c|}{ Área cultural } & \multirow{2}{*}{$\begin{array}{l}\text { Agente } \\
\text { causal } \\
\text { (artefacto } \\
\text { deformador) }\end{array}$} \\
\hline & & & Costeño & Andino & \\
\hline 2 & Fronto Occipital & $95.4 p$ & 3 & & Cuna \\
\hline 1 & Inca Costeño & 98.6 & & & \\
\hline 2 & Aimara & $\begin{array}{l}77.0 \\
72.5\end{array}$ & --- & 6 & Llautu \\
\hline 2 & Opa & $71.45 p$ & & & \\
\hline 2 & Cavernas & 95.2 & & & \\
\hline 2 & Huaura & $98.75 p$ & --- & 8 & Lautu + Rosca \\
\hline 2 & Cabeza Larga & $\begin{array}{l}81.2 \\
94.2\end{array}$ & & & Algodón Paracas \\
\hline 2 & Necrópolis & $93.7 p$ & & & \\
\hline 2 & Natchez & $\begin{array}{l}89.2 \\
82.9\end{array}$ & & & \\
\hline 1 & Nazca & 79.7 & --- & 1 & $\begin{array}{l}\text { Lautu + Rosca } \\
\text { Algodón Paracas } \\
\text { + Almohadilla }\end{array}$ \\
\hline 18 & & & 3 & 15 & \\
\hline
\end{tabular}

Tabla 4: Relación de índices craneanos de cráneos con deformación cefálica según tipología de Weiss con las tendencias morfocraneanas determinadas visualmente

\begin{tabular}{|c|c|c|c|c|c|}
\hline $\begin{array}{c}\mathrm{N}^{\circ} \text { de cráneos } \\
\text { (18) }\end{array}$ & $\begin{array}{l}\text { Cráneos deformados } \\
\text { Precolombinos } \\
\text { Tipología de Weiss }\end{array}$ & $\begin{array}{l}\text { Índice } \\
\text { Craneano }\end{array}$ & $\begin{array}{l}\text { Forma } \\
\text { craneana } \\
\text { (métrica) } \\
\text { Según Martin }\end{array}$ & $\begin{array}{l}\text { Forma } \\
\text { craneana } \\
\text { (métrica) } \\
\text { según Broca }\end{array}$ & $\begin{array}{l}\text { Forma } \\
\text { Craneana } \\
\text { (visual) }\end{array}$ \\
\hline 2 & Fronto occipital & $95.4 p$ & Hiperbraquicéfalo & Braquicráneo & Braquicéfalo \\
\hline 1 & Inca Costeño & 98.6 & Hiperbraquicéfalo & Braquicráneo & Braquicéfalo \\
\hline \multirow[t]{2}{*}{2} & Aimara & 77.0 & Mesocéfalo & Mesocráneo & Dolicocéfalo \\
\hline & & 72.5 & Dolicocéfalo & Dolicocráneo & Dolicocéfalo \\
\hline 2 & Opa & $71.45 p$ & Dolicocéfalo & Dolicocráneo & Dolicocéfalo \\
\hline 2 & Cavernas & 95.2 & Hiperbraquicéfalo & Braquicráneo & Braquicéfalo \\
\hline 2 & Huaura & $98.75 p$ & Hiperbraquicéfalo & Braquicráneo & Dolicocéfalo \\
\hline \multirow[t]{2}{*}{2} & Cabeza Larga & 81.2 & Braquicéfalo & Braquicráneo & Braquicéfalo \\
\hline & & 94.2 & Hiperbraquicéfalo & Braquicráneo & Braquicéfalo \\
\hline 2 & Necrópolis & $93.7 p$ & Hiperbraquicéfalo & Braquicráneo & Braquicéfalo \\
\hline \multirow[t]{2}{*}{2} & Natchez & 89.2 & Hiperbraquicéfalo & Braquicráneo & Braquicéfalo \\
\hline & & 82.9 & Braquicéfalo & Braquicráneo & Dolicocéfalo \\
\hline 1 & Nazca & 79.7 & Mesocéfalo & Sub-braquicráneo & Dolicocéfalo \\
\hline
\end{tabular}

Tabla 5: Relación de índices craneanos de cráneos con deformación cefálica según tipología de Weiss, formas craneanas visual y métricas de Martin y Broca con el área cultural y el agente causal

\begin{tabular}{|c|c|c|c|c|c|c|c|}
\hline $\begin{array}{l}N^{\circ} \text { de } \\
\text { cráneos } \\
(18)\end{array}$ & $\begin{array}{l}\text { Cráneos } \\
\text { deformados } \\
\text { precolombinos } \\
\text { Tipología de } \\
\text { Weiss }\end{array}$ & $\begin{array}{l}\text { Índice } \\
\text { craneano }\end{array}$ & $\begin{array}{l}\text { Forma craneana } \\
\text { (métrica) } \\
\text { Según Martin }\end{array}$ & $\begin{array}{l}\text { Forma } \\
\text { craneana } \\
\text { (métrica) } \\
\text { según Broca }\end{array}$ & $\begin{array}{l}\text { Forma } \\
\text { craneana } \\
\text { (visual) }\end{array}$ & $\begin{array}{l}\text { Área } \\
\text { cultural }\end{array}$ & $\begin{array}{l}\text { Agente } \\
\text { causal } \\
\text { (artefacto } \\
\text { deformador) }\end{array}$ \\
\hline 2 & Fronto occipital & $95.4 \mathrm{p}$ & Hiperbraquicéfalo & Braquicráneo & Braquicéfalo & Costeño & Cuna \\
\hline 1 & Inca Costeño & 98.6 & Hiperbraquicéfalo & Braquicráneo & Braquicéfalo & Costeño & Cuna \\
\hline \multirow[t]{2}{*}{2} & Aimara & 77.0 & Mesocéfalo & Mesocráneo & Dolicocéfalo & Andino & Llautu \\
\hline & & 72.5 & Dolicocéfalo & Dolicocráneo & Dolicocéfalo & & \\
\hline 2 & Opa & $71.45 p$ & Dolicocéfalo & Dolicocráneo & Dolicocéfalo & Andino & Llautu \\
\hline 2 & Cavernas & 95.2 & Hiperbraquicéfalo & Braquicráneo & Braquicéfalo & Andino & Llautu \\
\hline 2 & Huaura & $98.75 p$ & Hiperbraquicéfalo & Braquicráneo & Dolicocéfalo & Andino & \\
\hline \multirow[t]{2}{*}{2} & Cabeza Larga & 81.2 & Braquicéfalo & Braquicráneo & Braquicéfalo & Andino & \\
\hline & & 94.2 & Hiperbraquicéfalo & Braquicráneo & Braquicéfalo & & Llautu \\
\hline 2 & Necrópolis & $93.7 p$ & Hiperbraquicéfalo & Braquicráneo & Braquicéfalo & Andino & rosca algodón \\
\hline \multirow[t]{2}{*}{2} & Natchez & 89.2 & $\begin{array}{l}\text { Hiperbraqui- } \\
\text { céfalo }\end{array}$ & Braquicráneo & $\begin{array}{l}\text { Braquicé- } \\
\text { falo }\end{array}$ & Andino & \\
\hline & & 82.9 & Braquicéfalo & Braquicráneo & Dolicocéfalo & & \\
\hline 1 & Nazca & 79.7 & Mesocéfalo & $\begin{array}{l}\text { Sub-braqui- } \\
\text { cráneo }\end{array}$ & Dolicocéfalo & Andino & $\begin{array}{l}\text { Llautu + } \\
\text { rosca algodón } \\
\text { caracas+ } \\
\text { almohadilla }\end{array}$ \\
\hline
\end{tabular}




\section{Discusión}

El conocimiento de las deformaciones craneanas voluntarias y las posturales aumentan la comprensión de los mecanismos involucrados en las craniosinostosis.

Es interesante decir que mientras el equipo quirúrgico de hoy tiene como misión, en los casos de sinostosis, llevar el cráneo a su más normal morfología, los antiguos tenían como meta llevarlo a su mayor deformación

Alcanzaron al nivel de hiperbraquicéfalos (=/+ 85.0) de Martin ${ }^{17}$ los Frontoccipitales (95.4p), los Inca Costeño (98.6), los Cavernas (95.2), los Huaura (98.75p), los Cabeza Larga (94.2), los Necrópolis (93.7p) y los Natchez (89.2) de Weiss; equivalentes a los braquicráneos (81.33/+) de Broca ${ }^{1}$.

Al nivel de braquicéfalos (80-84.9) de Martin $^{17}$ alcanzaron un Cabeza Larga (81.2) y un Natchez (82.9) de Weiss, similar al subbraquicráneo (78.01-81.33) de Broca ${ }^{1}$.

En nuestro estudio no encontramos hiperdolicocéfalos (=/- 69.9) de Mar$\operatorname{tin}^{17}$, equivalentes a los dolicocráneos (75/-) de Broca ${ }^{1}$. Encontramos mesocéfalos (75-79.9) de Martin $^{17}$ a un Aimara (77.0) y un Nazca $(79,7)$ de Weiss, similares a los mesocráneos (75.78-78.01) de Broca ${ }^{1}$.

Los estudios de Marti indican que la altitud tiene un valor significativo sobre el índice craneano de modo que los Cabezas largas de 5,000 años de antigüedad que habitaban a $30 \mathrm{~m}$ de altura s.n.m. descritos por Hartweg ${ }^{7}$ presentaban un índice craneal promedio de 75.0; sin embargo fueron altos los índices craneanos (94.2), (81.2) encontrados en el presente estudio. Debido probablemente al elevado grado de deformación cefálica intencional, no obstante a la practica generalizada en aquellos años.

Sin embargo en una muestra de 600 aimaras los índices craneanos fluctúan entre 71.0 y $77.0^{6}$ similar al tipo aimara de Weiss que constituye parte de nuestra muestra de estudio.

De modo igual cráneos procedentes de Chancay $^{8}$, del Valle de Chicama, Moche y Virú $^{9}$ a $30 \mathrm{~m}$ de altura s.n.m., de 500 ańos de antigüedad, con índice craneal promedio de 79.5, similar al tipo Nazca de Weiss (79.7)

\section{Conclusiones}

Los cráneos peruanos precolombinos del área cultural costeño con deformación artificial por cuna presentan formas hiperbraquicéfalos según Martin con índice craneano promedio de 97.0, concordante con la percepción visual de su forma craneana.

Los cráneos peruanos precolombinos del área cultural andino con deformación cefálica artificial por llautu presentan formas dolicocéfalos según Martin con índice craneano promedio de 73.1, concordante con la percepción visual de su forma craneana.

Las formas craneanas determinadas por índice craneano son concordantes con las formas craneanas obtenidas visualmente por norma superior. Las discrepancias observadas podría deberse a la aplicación de artefactos semirrígidos que comprimían el opistocraneo, causando posiblemente la expansión longitudinal compensatoria del cráneo a expensas del lambda.

\section{Agradecimiento}

Nuestro sincero agradecimiento al $\mathrm{Mu}$ seo Nacional de Arqueología, Antropología e Historia del Perú, por las facilidades técnicas y administrativas que hicieron posible el logro de los objetivos del presente estudio

\section{Referencias bibliográficas}

1. Marti I, Rothhammer F. Variación del índice craneano en Sudamérica: contribuciones cronológicas, altitudinales y climáticas. Revista Chungará, Universidad de Tarapacá, Arica, Chile. 1987;18:181-187

2. Golalipour MJ. The Effect of Ethnic Factor on Cephalic Index in 17-20 Years Old Females of North of Iran. Int. J. Morphol. 2006; 24(3):319-322

3. Beals K. Head form and climatic stress. Am.J.Phys. Anthrop. 1972;37:85-92

4. Beals K. Climate and the evolution of brachycephalization. Am.J.Phys. Anthrop. 1983; 62:225-237

5. Testut L, Latarjet A. Anatomía humana. Barcelona: Salvat editores; Tomo 1, 1977. 700p

6. Valls A. Introducción a la antropología: fundamentos de la evolución y de la variabilidad biológica del hombre. Barcelona: Labor Universitaria; $1980.636 \mathrm{pp}$
7. Hartweg R. Les squelettes des sites sans ceramique de la cote du Pérou. I. Etude descriptive de documents nouveaux. Journ. De la Soc. des Americanistes. 1961; 50: 111-113.

8. Newman MA. Metric study of undeformed indian crania from Peru. Am. J. Phys. Anthrop. N S.1943; 1:21-45.

9. Stewart TD. Skletal remains with cultural associations from Chicama, Moche and Viry valleys, Perú. Proc. U.S. Nat. Mus. 1943; 93:153-185.

10. Mac Curdy G. Human skeletal remains from the high lands of Peru. Am. J. Phys. Anthrop. 1923; 6:217-329.

11. Llayperuma I. Evaluation of Cephalic Indices: A Clue for Racial and Sex Diversity. Int. J. Morphol.2011, 29(1):112-117

12. Gálvez CL, Maita VL, Guillen BC, Menéndez ML. Implicancia culturales en la morfología craneana en la morfología craneana de grupos étnicos precolombinos. Odontol Sanmarquina 2014;17(1):20-25

13. Borja VC, Gálvez CL. Deformaciones cefálicas en el antiguo Perú. Odontol Sanmarquina 2006;9(1):31-35

14. Vergara FL. Dos cráneos antiguos de Aimaraes. Revista Chilena de Historia Natural. 1898; 7(2):73-76

15. Posnansky A. Que es raza. Instituto <Tihuanaco > de Antropología, Etnografía y Prehistoria. Universidad Mayor de San Andrés. Bolivia 1942, 40p

16. Lapunzina P, Aiello H. Manual de Antropometría normal y patológica - Fetal, neonatal, niños y adultos. España: Elsevier. 2002. $503 \mathrm{p}$

17. Morel P. La Antropología Física. 2da. edición, Buenos Aires: Editorial Universitaria; $1968.117 \mathrm{p}$

18. García-Hernández F, MurphyEcheverría G. Índice craneano en grupos étnicos precolombinos del Norte de Chile con deformación craneal artificial. Int. J. Morphol. 2009; 27(2):587-594 